\title{
Cost Variation Analysis of Variance Brands of Anti-Alzheimer's Agents Currently Available in Indian Pharmaceutical Market
}

\author{
Kaur $\mathbf{M}^{1}$, Dhami $\mathbf{M}^{1}$, Singh $\mathrm{S}^{2}$, Gupta $\mathrm{GD}^{3}$ and Raj $\mathrm{K}^{1 *}$ \\ ${ }^{1}$ Scholar, Department of Pharmacology, ISF College of Pharmacy, India \\ ${ }^{2}$ Associate Professor, Department of Pharmacology, ISF College of Pharmacy, India \\ ${ }^{3}$ Professor, Department of Pharmaceutics, ISF College of Pharmacy, India
}

*Corresponding author: Khadga Raj, M. Pharm, Ph.D (Research Scholar), Assistant, Neuroscience Division, Department of Pharmacology, ISF College of Pharmacy, Moga, Punjab, India, 142001, Tel: +91-8288979902; Email: bishalarann@gmail.com

\section{Research article}

Volume 5 Issue 3

Received Date: October 12, 2020

Published Date: October 27, 2020

DOI: $10.23880 /$ ijbp-16000185

\section{Abstract}

Alzheimer's is a neurodegenerative disorder for which patients are expected to take medicines for longer period of time and even medicines for life time are often needed to treat this disease. Costly branding of drugs prescribed in such situation adds to the burden of illness and could even lead to failure of therapy compliance. The analysis was therefore designed to determine the cost of anti-Alzheimer's drugs of different brands and to examine price different between anti-Alzheimer's drugs on the India market. The cost of different brands of widely used anti-Alzheimer's drug was calculated by referring to the IDR. The cost of each brands 5 tablets in INR, cost ratio and percentage cost variance is determined. The difference between the highest and lowest price of the same drug produced by various pharmaceutical companies was measured as well as the percentage variance in cost for 5 tablets. The cost of total 5 anti-Alzheimer's drugs was analysed. There is more variation in the prices of different brands of same anti-Alzheimer's medicines in India market. The highest \% cost variation was found for Rivastigmine $1.5 \mathrm{mg}$ (195\%), Donepezil 5mg (114.28\%), Memantine 5mg (112\%) and lowest cost variation was Galantamine 4mg and Tacrine 10 $\mathrm{mg}(100 \%)$. Alzheimer's disease is most common neurodegenerative disease and drugs are to be prescribed for prolonged period. On the Indian market, the average price difference of different brands of the same anti-Alzheimer's medication is very high. If an expensive brand is prescribed, the patients must unnecessarily spend more money for their care. To combat such cost variability, physicians should be allowed to recommend a low-cost brand of medication. This effect reduces the patient's needless economic burden.

Keywords: Alzheimer's diseases; Cost- analysis; Cost variation

Abbreviations: AD: Alzheimer's disease; SDAT: Senile Dementia of the Alzheimer Type; DPCO: Drug Price Control Order; NPPA: National Pharmaceutical Pricing Authority.

\section{Introduction}

Alzheimer's disease (AD) is a primary degenerative disorder of the CNS which is characterised by impairment of memory [1] and eventually disturbances in learning capacity, reasoning, planning, language, thinking, judgement, calculation [2]. $\mathrm{AD}$ is the most common form of dementia, and is estimated to account for 60 to 80 percent of cases [3]. Recent studies have found indicate that about half of people with Alzheimer's dementia have brain changes (pathology) from $\mathrm{AD}$, as well as the brain changes from one or more other causes of dementia, [4] such as cerebrovascular disease or Lewy body disease [5]. AD is the seventh-leading cause of death and older and is also is a leading cause of disability and poor health [6]. In 2018, total affected by AD worldwide is estimated to be close to 50 million, this may nearly double 


\section{International Journal of Biochemistry \& Physiology}

every 20 years, reaching 75 million by 2030 and 131.5 million by 2050 . Per year there are over 9.9 million new cases of dementia worldwide. In India, 4 million new case every year [7]. AD is one of the major causes of morbidity, mortality and needs long-term treatment. The treatment of $\mathrm{AD}$ is a challenging task while selecting an appropriate drug or a combination of drugs, taking into account the cost of the drug. There is wide cost variation among different brands of the same AD drug. Clinician's awareness of cost of therapeutics is poor [8]. The expensive brand of same generic drug is proving to be in no way superior to its economically cheaper equivalent. The consideration of medication cost is an important aspect in health economics and plays a crucial role in patient's care especially in developing countries [9]. It is also an essential part of rational drug prescription influencing compliance with treatment. The availability of drugs in various dosage forms with different brands with more cost variation in India creates a lot of problems for the physicians in choosing the less costly drug for individual patients [10]. The awareness of cost variation of Alzheimer drugs can be applied for more economical treatment regimen to improve the patient compliance and decrease the rate of failure of therapy. The paucity of literature on cost effective analysis of anti-Alzheimer drugs implies needed for cost analysis of available formulations of antiAlzheimer drugs in the practice of medicine and hence the above study was designed [11]. During last few decades the demand for healthcare has increased rapidly resulting in high expenditure. To spend financial resources as efficiently as possible, cost containment has assumed significant importance [12]. The consideration of cost of treatment is an important aspect of health economics. The cost of drug is an important factor, especially in developing countries. The most basic cost of a drug is reflected in the acquisition price from a supplier [13].

AD is a most common caused by Dementia. Dementia is diagnosed when such symptoms are sufficient to hinder everyday life's personal activities. It is also known as Senile Dementia of The Alzheimer Type (SDAT) [14]. The cause of $\mathrm{AD}$ is poorly unknown, about $70 \%$ of the risk is believed to be inherited from a person's parents with many genes like APP, APOE, PSEN1, PSEN2 usually involved [15] other risk factors: Head injuries, depression, hypertension (uncontrolled high blood pressure may cause problems by damaging and narrowing the blood vessels in brain).

The treatment of Alzheimer's is a challenging task while selecting an appropriate drug that controls it to spread the disease into other parts of brain [16]. The consideration of medication cost is an important aspect in health economics and plays a crucial role in patient's care especially in developing countries [17]. It is also an essential part of rational drug prescription influencing compliance with treatment [18]. Availability of anti-Alzheimer's drugs under various dosage forms with different labels with more cost difference in India creates a lot of problems for the doctors in selecting the less costly medication for patients [19]. Due to increased cost variation in the anti-Alzheimer's drugs, there is decreased compliance and consequently leads to decrease in the quality of life, adding to the economic burden for patients. The awareness of cost variation of anti-Alzheimer's drugs can be applied for more economical treatment regimen to improve the patient compliance and decrease the rate of failure of therapy [20]. The paucity of literature on cost effective analysis of anti-Alzheimer's drugs implies the need for cost analysis of available formulations of anti-Alzheimer's drugs in the practice of medicine and hence the above study was designed. This study aims to analysis cost variation of various brands of anti-Alzheimer's drugs currently available in Indian pharmaceutical market.

\section{Methods}

This was an analytical study (Current index) was referred to analyze the maximum and minimum price of antiAlzheimer's drugs in all available strengths and dosage types are produced in India by different companies [21].

These drug formulations with same strength, dose and number were included for the study [22]. The drugs being manufactured by only one company and fixed dose combinations were excluded. Further analysis was done by using percentage cost variation of the costliest to cheapest of the various brands of anti-Alzheimer drug [21]. From this we can know that how many times the costliest brand costs more than the cheapest brand in each group.

Percentage cost variation was calculated as follows: $[23,24]$.

$$
\text { Cost variation }(\%)=\frac{\text { Maximum cost }- \text { Minimum cost } \times 100}{\text { Minimum cost }}
$$

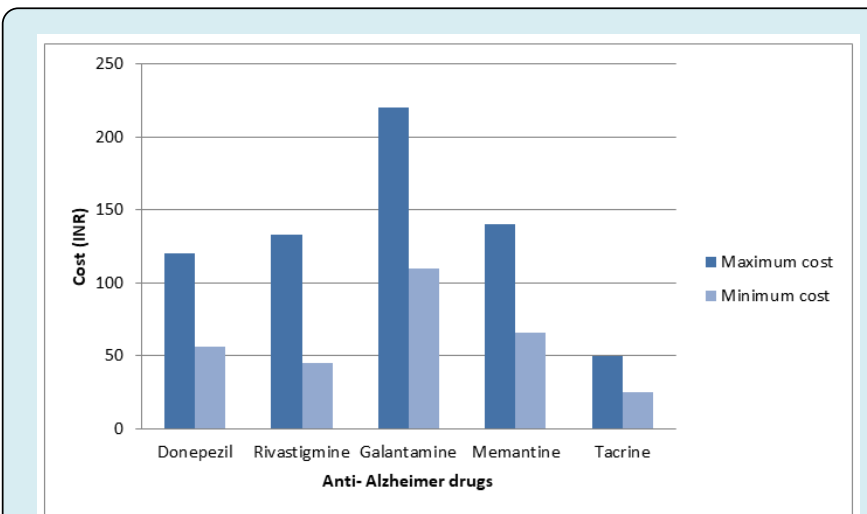

Figure 1: Cost difference [min and max] commonly used anti-alzheimer's drugs used as a single drug therapy. 


\section{International Journal of Biochemistry \& Physiology}

\begin{tabular}{|c|c|c|c|c|c|}
\hline Drugs & Composition & Company & Packing & $\begin{array}{c}\text { MRP (Maximum rate and Minimum } \\
\text { rate) }\end{array}$ & Ratio \\
\hline Donepezil & $5 \mathrm{mg}$ & Solus & 10 & Max.= Rs. 120, Min.= Rs. 56 & $114.28 \%$ \\
\hline Rivastigmine & $1.5 \mathrm{mg}$ & Sun Pharma & 10 & Max. = Rs.133, Min. = Rs. 45 & $195 \%$ \\
\hline Galantamine & $4 \mathrm{mg}$ & Sun Pharma & 10 & Max. =Rs. 220, Min. $=$ Rs. 110 & $100 \%$ \\
\hline Memantine & $5 \mathrm{mg}$ & Bondane Pharma & 10 & Max. $=$ Rs.140, Min. $=$ Rs. 66 & $112 \%$ \\
\hline Tacrine & $10 \mathrm{mg}$ & Intas & 10 & Max. = Rs. 50, Min. $=$ Rs. 25 & $100 \%$ \\
\hline
\end{tabular}

Table 1: Percentage cost variation of commonly used anti-alzheimer's drugs

\section{Results}

The prices of anti-Alzheimer drugs manufactured by different pharmaceutical companies were analysed. The present study showed a very high variation in the maximum and minimum price of anti- Alzheimer drugs which is being manufactured by several different companies in India. There is more variation in the prices of different brands of same anti-Alzheimer's agents in Indian market, shown in table 1 . The highest $\%$ cost variation was found for Rivastigmine $1.5 \mathrm{mg}$ (195\%), Donepezil $5 \mathrm{mg}$ tablet (114.28\%), Memantine $5 \mathrm{mg}(112 \%)$ and lowest $\%$ cost variation was of Galantamine $4 \mathrm{mg} \&$ Tacrine $10 \mathrm{mg}(100 \%)$.

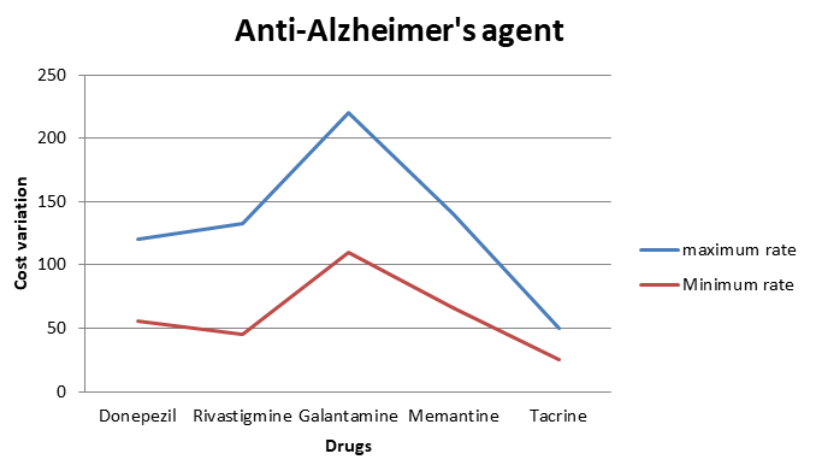

Figure 2: Cost diffrence [min and $\max ]$ used antialzheimer's drugs

\section{Discussion}

The present study showed a very high variation in the maximum and minimum price of anti-Alzheimer drugs (Figures $1 \& 2$ ). The percentage variation in the cost was above $100 \%$ with most of the anti- Alzheimer's drugs and there is substantial variation in the cost of different brands of same anti-Alzheimer's drugs in Indian market. Higher medication cost has been found to be a reason for medication non-adherence. Medication non-compliance can be the single most common reason for treatment failure in Alzheimer. It has been estimated that up to $60 \%$ of patients with Alzheimer are non-compliant. Non-compliance of the drug therapy results in progression of the disease which increases the overall medical care costs dramatically [25]. The expensive brand of same generic drug is clinically proven to be in no way superior to its cheaper economical equivalent [26]. Prescribing doctors should pay due importance to the drug prices in a country like India where majority of patients are paying out of their pockets for their medical bills and are not covered by insurance schemes. It has been found that more than $80 \%$ health financing is borne by patients in India. In such situation if costly brands are prescribed patients has to pay unnecessarily more money and that creates an economic burden [27]. The situation can be improved if drug cost is given greater emphasis during medical training program of doctors. Currently, very few medications are under drug prices control order. Government should bring more number of anti-Alzheimer's drugs under price control. Drug Price Control Order (DPCO) and the National Pharmaceutical Pricing Authority (NPPA) are effective tools for regulation of drug prices.

\section{Conclusion}

The present study showed a more variation in the prices of different brands of same anti-Alzheimer's drugs currently available in Indian market. Increased adherence to the treatment can be ensured by decreasing the cost of therapy [28] by changes in the government policies and regulation and creating awareness among treating physicians for switching to cost effective therapy and thus help in rational prescribing [29].

Prescribing medications should be given greater emphasis among practitioners and also spreading awareness that cheaper medicines are not inferior to costlier branded counterparts. Financial constraints are a reality in almost all aspects of medicine. Doctors have to consider the cost of medications to their patients. Patients are adversely affected by raising medication costs. Given the increasing cost of healthcare, there is growing interest in appropriate prescribing, taking into account prescription costs [30]. 


\section{International Journal of Biochemistry \& Physiology}

\section{References}

1. Masliah E (1995) Mechanisms of synaptic dysfunction in Alzheimer's disease. Histol Histopathol 10(2): 509-519.

2. Obi JC, Imainvan AA (2011) Decision support system for the intelligent identification of Alzheimer using neuro fuzzy logic. International Journal on Soft Computing 2(2): 25-38.

3. Alzheimer's Association (2017) 2017 Alzheimer's disease facts and figures. Alzheimer's \& Dementia 13(4): 325-373.

4. Joachim CL, Morris JH, Selkoe DJ (1988) Clinically diagnosed Alzheimer's disease: autopsy results in 150 cases. Ann Neurol 24(1): 50-56.

5. Bétard C, Robitaille Y, Gee M, Tiberghien D, Larrivée D, et al. (1994) Apo E allele frequencies in Alzheimer's disease, Lewy body dementia, Alzheimer's disease with cerebrovascular disease and vascular dementia. Neuroreport 5(15): 1893-1896.

6. Alzheimer's Association (2016) 2016 Alzheimer's disease facts and figures. Alzheimers Dementia 12(4): 459-509.

7. Dai B, Larnyo E, Tetteh EA, Aboagye AK, Musah AAI (2020) Factors Affecting Caregivers' Acceptance of the Use of Wearable Devices by Patients with Dementia: An Extension of the Unified Theory of Acceptance and Use of Technology Model. Am J Alzheimers Dis Other Demen 35: 1533317519883493.

8. Allan GM, Lexchin J, Wiebe N (2007) Physician awareness of drug cost: a systematic review. PloS Med 4(9): e283.

9. Kesselheim AS, Avorn J, Sarpatwari A (2016) The high cost of prescription drugs in the United States: origins and prospects for reform. JAMA 316(8): 858-871.

10. Srinivas N, Maffuid K, Kashuba AD (2018) Clinical pharmacokinetics and pharmacodynamics of drugs in the central nervous system. Clin Pharmacokinet 57(9): 1059-1074.

11. Weisbrod BA (1991) The health care quadrilemma: an essay on technological change, insurance, quality of care, and cost containment. Journal of economic literature 29(2): 523-552.

12. Foster SD (1991) Pricing, distribution, and use of antimalarial drugs. Bulletin of the World Health Organization 69(3): 349.

13. Patricia PN, Vitaliano PP, Vitiello MV, Bokan J, Raskind M, et al. (1982) Sleep, EEG and mental function changes in senile dementia of the Alzheimer's type. Neurobiology of Aging 3(4): 361-370.

14. Lanoiselée HM, Nicolas G, Wallon D, Rovelet-Lecrux A, Lacour M, et al. (2017) APP, PSEN1, and PSEN2 mutations in early-onset Alzheimer disease: A genetic screening study of familial and sporadic cases. PLoS Med 14(3): e1002270.

15. Hampel H, Prvulovic D, Teipel S, Jessen F, Luckhaus C, et al. (2011) The future of Alzheimer's disease: the next 10 years. Prog Neurobiol 95(4): 718-728.

16. Folland S, Goodman AC, Stano M (2016) The Economics of Health and Health Care: Pearson New International Edition. Routledge.

17. Buck D, Jacoby A, Baker GA, Chadwick D W (1997) Factors influencing compliance with antiepileptic drug regimes. Seizure 6(2): 87-93.

18. Fortanasce V (2008) The anti-Alzheimer's prescription: The science-proven plan to start at any age. Penguin.

19. Si Silva AC, González-Mira E, Lobo JS, Amaral MH (2013) Current progresses on nanodelivery systems for the treatment of neuropsychiatric diseases: Alzheimer's and Schizophrenia. Curr Pharm Des 19(41): 7185-7195.

20. Linden LP (2014) Pharmaceutical industry perspectives on factors that influence the adoption and diffusion of drugs in the UK: four case studies. Doctoral dissertation, University of Birmingham, pp: 1-549.

21. Banode S, Chourishi A (2016) Cost analysis of antiepileptic drugs of different brands available in India. Int J Sci Res 5(2): 281-282.

22. Panchal SS, Pandit PR, Phatak AM, Lohi KM (2015) Cost analysis of antiretroviral agents available in India. Int J Basic Clin Pharmacol 4(3): 479-482.

23. Akila L, Rani RJ (2015) Cost analysis of different brands of antianginal drugs available in India. Int J Basic Clin Pharmacol 4(5): 860-863.

24. Small G, Dubois B (2007) A review of compliance to treatment in Alzheimer's disease: potential benefits of a transdermal patch. Curr Med Res Opin 23(11): 27052713.

25. Kamath L, Satish GR (2016) Cost variation analysis of antihypertensive drugs available in Indian market: An economic perspective. International Journal of Pharmaceutical Sciences and Research 7(5): 2050. 


\section{International Journal of Biochemistry \& Physiology}

26. KamatVR, Nichter M (1998) Pharmacies, self-medication and pharmaceutical marketing in Bombay, India. Soc Sci Med 47(6): 779-794.

27. Tayeb HO, Yang HD, Price BH, Tarazi FI (2012) Pharmacotherapies for Alzheimer's disease: beyond cholinesterase inhibitors. Pharmacol Ther 134(1): 8-25.
28. Hogerzeil HV (1995) Promoting rational prescribing: an international perspective. Br J Clin Pharmacol 39(1): 1-6.

29. Nyman JA (1985) Prospective and 'cost-plus' Medicaid reimbursement, excess Medicaid demand, and the quality of nursing home care. J Health Econ 4(3): 237259. 